\title{
Localization of the modified base J in telomeric V SG gene expression sites of Trypanosoma brucei
}

\author{
Fred van Leeuwen, Eric R. Wijsman, ${ }^{1}$ Rudo Kieft, Gijs A. van der Mare, ${ }^{1}$ Jacques H. van Boom, ${ }^{1}$ \\ and Piet Borst ${ }^{2}$ \\ Division of Molecular Biology, The N etherlands Cancer Institute, 1066 CX Amsterdam, The N etherlands; ${ }^{1}$ Leiden Institute \\ of Chemistry, Gorlaeus Laboratories, 2300 RA Leiden, The N etherlands
}

\begin{abstract}
African trypanosomes such as Trypanosoma brucei undergo antigenic variation in the bloodstream of their mammalian hosts by regularly changing the variant surface glycoprotein NSG ) gene expressed. The transcribed V SG gene is invariably located in a telomeric expression site There are multiple expression sites and one way to change the VSG gene expressed is by activating a new site and inactivating the previously active one. The mechanisms that control expression site switching are unknown, but have been suggested to involve epigenetic regulation. We have found previously that V SG genes in silent (but not active) expression sites contain modified restriction endonuclease cleavage sites, and we have presented circumstantial evidence indicating that this is attributable to the presence of a novel modified base $\beta$-D-glucosyl-hydroxymethyluracil, or J. To directly test this, we have generated antisera that specifically recognize J-containing DNA and have used these to determine the precise location of this modified thymine in the telomeric VSG expression sites. By anti J-DNA immunoprecipitations, we found that J is present in telomeric VSG genes in silenced expression sites and not in actively transcribed telomeric V SG genes. J was absent from inactive chromosome-intemal V SG genes. DNA modification was also found at the boundaries of expression sites. In the long 50-bp repeat arrays upstream of the promoter and in the telomeric repeat arrays downstream of the VSG gene, J was found both in silent and active expression sites. This suggests that silencing results in a gradient of modification spreading from repetitive DNA flanks into the neighboring expression site sequences. In this paper, we discuss the possible role of $J$ in silencing of expression sites.
\end{abstract}

[Key Words: DN A modification; silencing; antigenic variation; VSG; sequence repeats]

Received July 17, 1997; accepted in revised form September 9, 1997.

Trypanosoma brucei is a protozoan parasite that lives in the blood of mammals and causes sleeping sickness in man. By regularly changing the variant surface gl ycoprotein (VSG) coat, African trypanosomes can evade immunodestruction by the host, as reviewed in Cross (1996). Each trypanosome has hundreds of VSG genes but usually expresses only one at a time. The active VSG gene is exclusively located in one of the up to 20 telomeric VSG expression sites (for review, see Pays et al . 1994; Borst et al. 1997). These large transcription units are highly homologous and include several expression site-associated genes (ESAGs), besi des a VSG gene (Revel ard et al . 1990). The VSG coat can be changed by replacing the VSG gene in the active expression site, or by activating a new expression site and silencing the old one. Expression site switching can occur without any detectable DNA rearrangements (Zomerdijk et al. 1990; Horn and Cross 1997). How bloodstream trypanosomes silence all VSG

${ }^{2}$ Corresponding author.

FAX 31-20-669-1383. expression sites but one and how the transcriptional states are stably inherited is not known (for review, see Borst et al. 1997). The promoter sequence independence of expression site control, however, suggests that an epigenetic mechanism such as telomere position effect might be involved (Horn and Cross 1995; Rudenko et al. 1995).

Silencing of an expression site is accompanied by DNA modifications in and around inactivated telomeric VSG genes (see Fig. 1A). These DN A modifications were deduced from partial cleavage of Pstl, Pvull (Bernards et al. 1984b), and sometimes HindlII and Sphl restriction sites (Pays et al. 1984). The restriction site polymorphisms were not found in transcribed VSG genes near telomeres or in silent chromosomeinternal VSG genes, and were only present in bloodstream form (BF) trypanosomes. In insect form (or procyclic, PC) trypanosomes, which have a different coat protein and do not transcribe VSG genes, no modification was found (Pays et al. 1984). Modification at a given site was partial, that is, it was present in only a fraction of the cells in a clonal trypano- 
A
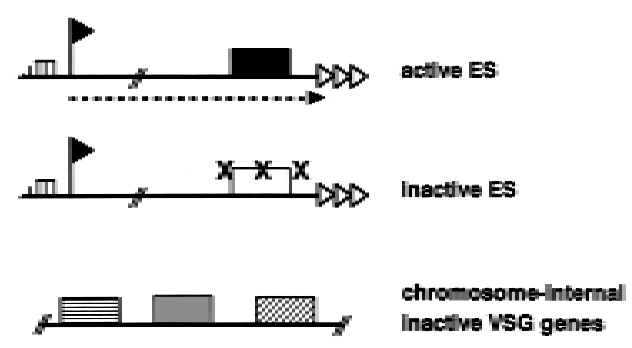

B

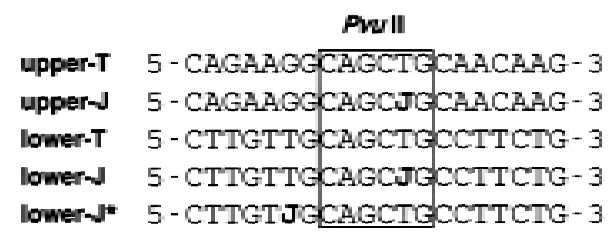

c

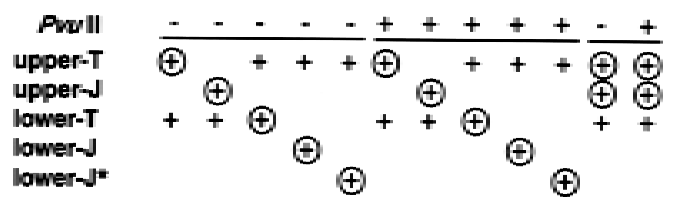

ds

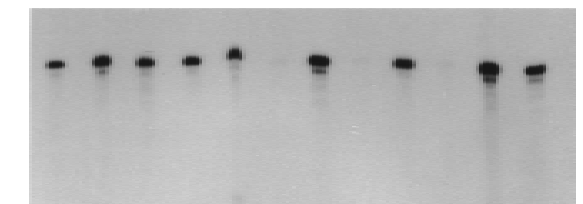

cleaved

(ss)

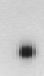

Figure 1. The modified base J prevents cleavage by Pvull. (A) Partial cleavage by restriction enzymes Pstl, Pvull, and other enzymes (see text) suggested that silenced expression sites acquire a DNA modification $(\mathbf{X})$ in and around the inactive telomeric VSG gene (box). These blocked restriction sites are not found in transcribed expression sites (broken line with arrowhead) or in silent chromosome-internal VSG genes. Telomeric repeats are indicated by triangles, the expression site promoter by a flag, and the imperfect tandem 50 -bp repeats by a hatched box. (B) The effect of substitution of $T$ by $J$ on digestion of duplex DNA by Pvull restriction endonuclease; 20-mer oligonucleotides with a central Pvull restriction site (box) were used as substrates. If present, J replaced T in the Pvull site in either the upper or the lower strand, or replaced T two positions downstream of the Pvull site in the lower strand (lower-J*). (C) Endlabeled oligomers (circled plus signs) were annealed to their nonlabel ed complementary strands (+) to form duplex ol igomers (ds), which were incubated without ( $\rightarrow$ or with (+) Pvull enzyme. Substrate and products were separated by native $20 \%$ polyacrylamide gel electrophoresis. Cleavage at $37^{\circ} \mathrm{C}$ resulted in short fragments that melted to single-stranded molecules at this temperature (cleaved ss). The last two lanes show a mixing control of duplexes with and without J. Incubation with Pvull (+) resulted in a noncleaved and a cleaved product. some population, and this fraction increased with the length of the associated telomeric repeat tract (Bernards et al. 1984b).

The recently identified unusual base $\beta$-D-glucosyl-hydroxymethyluracil ( $\beta$-gluc-HOM eU), cal led J (GommersAmpt et al. 1991, 1993), is a good candidate for this telomere-linked DN A modification. This modified base, detected by ${ }^{32} \mathrm{P}$-nucleotide postlabeling combined with separation on two-dimensional thin-layer chromatography, has only been found in DNA of African trypanosomes. It is present at low levels $(0.2 \mathrm{~mole} \%)$ in BF trypanosomes and is absent from PC trypanosomes (Gommers-Ampt et al. 1991). By nucleotide postlabeling analysis of purified telomeric tracts, we have shown re cently that about half of all $\mathrm{J}$ is concentrated in both strands of the telomeric (GGGTTA) repeats (van Leeuwen et al. 1996). Besides J and its putative precursor HOMeU, no other DNA modifications, such as DNA methylation, have been found in $\mathrm{T}$. brucei (Crozatier et al. 1988; Gommers-Ampt et al. 1991; van Leeuwen et al. 1996). We have now verified that J prevents cleavage by restriction endonucl ease Pvull. With anti sera specific for $\mathrm{J}$-containing DNA, we have located $\mathrm{J}$ in and around the telomeric VSG expression sites.

\section{Results}

J prevents cleavage by restriction endonuclease Pvul I

Partial cleavage of restriction sites suggested the presence of a DNA modification in silenced telomeric VSG genes in bloodstream T. brucei (see Fig. 1A). The modified base J has the properties expected for the postulated modification, as a bulky base such as J may be expected to block cleavage by restriction enzymes (Huang et al. 1982). We have tested whether J blocks cleavage by Pvull, using DNA duplexes of short ol igonucleotides encoding the Pvull site and its flanking sequences of VSG gene 221 (Fig. 1B). Figure 1C shows that duplexes with a hemimodified Pvull site were not cleaved, whereas duplexes without J were digested completely. J replacing T two positions downstream of the Pvull site did not block cleavage, showing that J at a short distance does not affect the endonuclease-DNA interaction. Pstl has been shown al ready to be sensitive to the presence of $\mathrm{HOM} \mathrm{eU}$ in the target sequence (McClelland et al. 1994) and is therefore expected to be also sensitive to $\mathrm{J}$. These results confirm that J can block cleavage by restriction endonucleases and support further the correlation between J and the postulated modification in tel omeric VSG genes. They do not, however, prove that J is present in VSG expression sites. Because restriction site polymorphisms and genomic sequencing (see Discussion) do not exclude the presence of other modifications, we set out to generate J-specific antisera to make it possible to detect low amounts of $\mathrm{J}$ in unique sequences in the genome.

\section{Generation of antisera specific for J-containing DNA}

To obtain antinucleic acid antisera with a high specificity for DNA containing J in various sequence contexts, 
we induced antibodies with nucleotide-protein immunizing conjugates (see $M$ aterials and $M$ ethods). Immunization with J-5'-monophosphate (JMP) conjugated to keyhole limpet haemocyanin $(\mathrm{KLH})$ or to bovine serum albumin (BSA) resulted in polyclonal rabbit antisera $538 \alpha$ J and $539 \alpha$ J, respectively. The specificity and sensitivity of the antisera were tested on DNA dot-blots with dilution series of various DNA samples, using immunodetection combined with enhanced chemiluminescence. With both antisera we could detect less than one J in $10^{6}$ bases on dot-blots (Fig. 2A). This is at least 100-fold more sensitive than nucleotide postlabeling. 538 $\alpha$ J and 539 $\alpha$ J did not recognize DNA from Escherichia coli, calf thymus, or PC T. brucei, showing that they do not crossreact with nonmodified or methylated DNA, and confirming that PC trypanosomes are devoid of J (Fig. 2B). The antisera weakly recognized nonglucosylated HOMeU because some cross-reaction was found with phage $\phi$ e DNA, in which all thymines are replaced by $\mathrm{HOMeU}$. A stronger cross-reaction was found with $\beta$ glucosyl-hydroxymethylcytosine ( $\beta$-gluc-HOMeC), but not with $\alpha$-gluc-HOM eC, bases found in T-even phages. In bacteriophages T 2 and T4, HOM eC replaces $C$ (Kornberg et al. 1961). In both phages, 70\% of HOM eC is $\alpha-$ glucosylated, in phage T 4 another $30 \%$ is $\beta$-glucosylated. The glucosylated cytosine variants have only been found in T-even phage DN A and can be distinguished from J by ${ }^{32} \mathrm{P}$-nucleotide-postlabeling combined with two-dimensional thin-layer chromatography (Gommers-Ampt et al . 1991). Partially deaminated T 2 DN A, in which a fraction

A

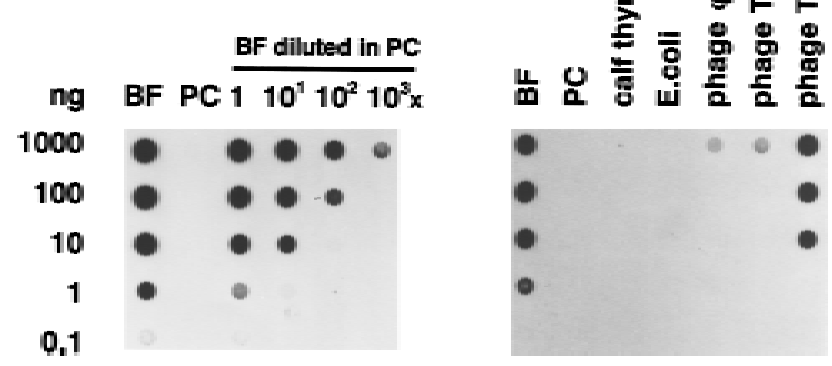

Figure 2. Detection of J-containing DNA on filters with polyclonal anti-J antisera. Dot-blots with dilution series of denatured DNA were incubated with polyclonal antiserum 539 $\alpha$ J and bound antibodies were detected with sheep $\alpha$-rabbit-HRP in combination with enhanced chemiluminescence. (A) The sensitivity of detection was determined with a dilution series of BF trypanosome DNA (0.2 mole\% J) and PC DNA (no J), and BF DNA diluted in PC DNA. Less than $0.0002 \mathrm{~mole} \% \mathrm{~J}$ could be detected. Hybridization with a telomere repeat probe showed that equal amounts of DNA were present in each dilution series (data not shown). (B) Specificity of the antisera was tested with DNA samples with various DNA modifications: calf thymus (5-methylC), E. coli (6-methylA, 4-methylC, 5-methylC), phage фe (HOMeU), phage T2 (HOM eC, $\alpha$-gluc- and $\beta$-gluc- $\alpha$-glucHOM eC), phage T4 ( $\alpha$ - and $\beta$-gluc-HOM eC). Pre-immune sera gave no signal at all (data not shown). of $\alpha$-gluc-HOMeC was converted into $\alpha$-gluc-HOMeU $(0.1 \%-11 \%$ of $\mathrm{T})$ did not cross-react, showing that the antibodies react specifically with $\beta$-glucose linked to HOMeU or HOMeC (data not shown).

\section{Immunoprecipitation of modified DNA}

Immunoblots with denatured DNA provide a sensitive tool for the detection of J in DNA, but are less useful to study J-modification of specific sequences in a genome. We therefore tested whether the antibodies would immunoprecipitate J-containing double-stranded DNA fragments. Duplex DNA fragments of 118, 426, and 943 $\mathrm{bp}$, each with one J residue, were generated by PCR amplification of part of the 221 VSG gene using one antisense primer with J and three different sense primers without J (Fig. 3A). As a negative control, the shortest fragment was amplified with two J-less primers. The 118-bp PCR products were ligated to each other to obtain a ladder of fragments of different sizes but with the same J density. Fragments were end-labeled, incubated with $\alpha$ J antisera, and antibody-DNA complexes were captured by protein-A beads. Bound DNA was released by protease treatment and phenol extraction, separated by agarose gel-electrophoresis, and then blotted (Fig. 3B). One J residue was sufficient to immunoprecipi tate a fraction of the duplex DNA molecules (Fig. 3B, lanes 1,2) and this fraction decreased with length. The effect of length was less if the density of modification was kept constant (Fig. 3B, Ianes 3,4). DNA without J was not immunoprecipitated (Fig. 3B, lane 5,6). Quantitation of the relative efficiency of immunoprecipitation (IP) of the various fragments (Fig. 3C) showed that anti-J IP is dependent on the size of the target fragment and the degree of modification.

Having the tools to select for J-containing DNA, we set out to analyze modified genomic restriction fragments from BF T. brucei DNA. Because we had found previ ously that the tel omeric repeats contain about 4\% J compared with $0.2 \% \mathrm{~J}$ in the total genome (van Leeuwen et al. 1996), we first tested the long telomeric repeat arrays and found that despite thei $r$ length (2-26 kb) these were immunoprecipitated readily (see below). Furthermore, immunoprecipitation of sonicated T. brucei DNA resulted in up to 20 -fold enrichment for J (data not shown).

\section{$\mathrm{J}$ is present in silenced telomeric VSG genes}

To test whether $\mathrm{J}$ is present in the silenced telomeric VSG genes, we used three related BF trypanosome clones, each expressing a different VSG gene. One PC clone, not expressing any VSG gene and devoid of any modification was used as a negative control. Maps of the VSG genes, which are present in all four clones, are depicted in Figure 4A. 121a BF cells express VSG gene 121 (expression linked copy or ELC) in the dominant expression site (Liu et al. 1985). All four clones have three additional silent chromosome-internal VSG 121 genes (basic copies or BCs). 221a BF cells, which express the single-copy VSG gene 221 in the 221 expression site, 
A

B

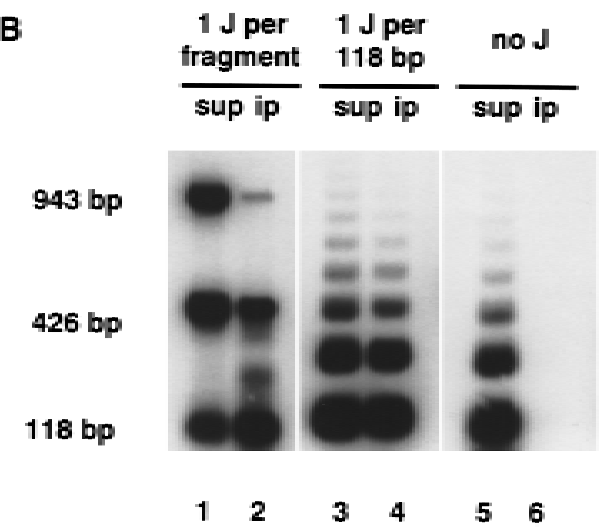

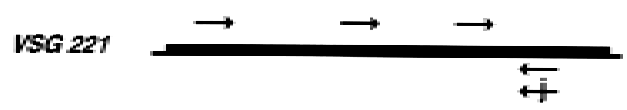

C

\begin{tabular}{ccc} 
Size & $d$ & \%IP \\
\hline 1118 & 0 & 0 \\
1118 & 1 & $3.8 \pm 0.6$ \\
236 & 2 & $3.4 \pm 1.0$ \\
354 & 3 & $3.0 \pm 0.7$ \\
$4 \pi 2$ & 4 & $2.8 \pm 0.6$ \\
\hline 118 & 1 & $5.6 \pm 2.3$ \\
426 & 1 & $23 \pm 0.2$ \\
943 & 1 & $0.6 \pm 0.3$
\end{tabular}

arose from cl one 121a by an in situ switch. r5-1.1 BF cells express the single-copy VSG gene 1.1 and arose from clone 221 a by a complex event (see $M$ aterials and $M$ ethods). The inactive 221 gene at its new location is not modified on its Pvull site and is not sensitive to Bal31 exonuclease treatment, showing that the 221 gene had been transposed to a chromosome-internal position in clone r5-1.1 (data not shown).

Figure 4B shows the results of immunoprecipitations of the three VSG genes studied. Genomic DNA of all clones was digested with various restriction enzymes to obtain small VSG gene fragments. These restriction fragments were analyzed by anti-J IP combined with Southern bl ot hybridization. In all BF clones, the actively transcribed VSG gene was not bound by antibodies, whereas silenced tel omeric VSG genes were invariably immunoprecipitated. These results show a clear correlation between base J and telomeric gene repression.

Whereas the inactive telomeric 221 gene in 121 a cells (Fig. 4B), and in 221aR 12, 118a, and 118a' cells (data not shown) was efficiently bound by antibodies, the silenced chromosome-internal 221 gene in r5-1.1 cells was not detectably bound by the antisera. This indicated that $\mathrm{J}$ is absent from chromosome-internal VSG genes. We confirmed this by analysis of the silent chromosome-internal 121 gene copies (BC), which can be separated from each other and from the ELC by a HindlII digest. $\mathrm{N}$ one of the 121 BC genes was immunoprecipitated, whereas the ELC, here linked to the telomeric repeats, was pulled down (Fig. 4C; see bel ow). The same lack of immunoprecipitation was found for the chromosome-internal basic copy of VSG gene 1.8 (data not shown). Together, the results from Figure 4, $B$ and $C$, show that the inverse correlation between the presence of J and VSG gene activity holds true only for telomeric VSG genes, in agreement with the distribution of blocked restriction sites.
Telomere repeat arrays associated with inactive as well as active expression sites are modified

We have found previously that about half of $\mathrm{J}$ is present in telomeric repeats. Approximately $80 \%$ of the telomeres are part of minichromosomes (Van der Ploeg et al. 1984) and the analysis of telomeric repeats is therefore dominated by these minichromosomes, which do not contain functional VSG gene expressi on sites (Zomerdijk et al. 1990). To test whether the tel omeric repeat arrays associated with expression sites were also modified, we analyzed restriction digests of genomic DNA in which the expression-linked VSG genes were still associated with the telomeric repeat arrays. This allowed the unique VSG sequences to be used as specific probes for individual telomere tracts. Thelength of these fragments varies between different clones because telomeres in trypanosomes grow and contract on cell division, resulting in clonal variation and heterogeneity of the size of the telomeric repeat arrays (Bernards et al. 1983). The results in Figure 4D show that VSG genes linked to telomeric repeats were immunoprecipitated efficiently. Unexpectedly, however, this occurred irrespective of the transcriptional state of the upstream expression site. Because transcribed VSG genes al one were not modified (Fig. 4B), these results show that the hexameric repeat tracts flanking active expression sites are modified. The efficient antibody binding of the long telomeric tracts of active and inactive sites shows that both must contain a similarly high degree of modification. This is in agreement with the $2 \%-4 \%$ J found in purified telomeric repeat arrays (van Leeuwen et al. 1996). The lack of IP of the PC 1.1 telomere in a mix of PC DNA and BF 221a DNA excludes the possibility that nonmodified telomeres nonspecifically coimmunoprecipitated with modified DNA (Fig. 4D). It has been suggested that tran- 
Figure 4. Localization of $\mathrm{J}$ at the telomeric end of VSG expression sites by anti-J immunoprecipitation. (A) Restriction maps of VSG genes 121,221 , and 1.1, expressed in BF clones 121a, 221a, and $r 5-1.1$ respectively. These genes are present in all clones analyzed here, including the PC clone, which was used as a negative control. In addition to the ELC of VSG 121, three chromosome-internal basic-copy (BC) 121 genes are present in all clones. In clone r5-1.1, the 221 gene has moved from its telomeric position in the expression site to a chromosome-internal position where the Pvull site is no longer modified (see text). (Solid boxes) Coding sequence; (open triangles) telomeric repeat arrays, of which the length varies per clone and per telomere. The VSG gene-specific probes are indicated underneath the coding sequences. (B) Bgll; (C) Clal; (D) Dral; (E) EcoRI; (H) HindIII; (N) Ncol. (B) Immunoprecipitation of VSG genes al one. DNA of the clones indicated at the top was digested with restriction enzymes shown on the right of each panel. Modified DNA fragments bound by the anti-J antibodies (ip) and $10 \%$ of the supernatant (sup) were analyzed by Southern bl ot hybridization. The VSG gene on the left of each panel indicates the probe used (probe fragments are shown in A). N ote that the one telomeric copy and three basic copies of VSG gene 121 cannot be discriminated in the BglI-Ncol digest used for this VSG gene. (C) Analysis of modification of the three chromosome-internal BCs and the telomeric ELC of VSG gene 121 by $\alpha$ J-IP of HindlII restriction fragments. A size marker is indicated on the right. (D) Analysis of the tel omeric repeat arrays associated with expression sites. The fragments were detected by hybridization with probes specific for the VSG genes still linked to the telomeric tracts. The restriction digests, the VSG genes probed for, and a size marker are shown on the left of each panel. As a control, PC DN A was mixed with BF 221a DNA and probed for 1.1 to show that nonmodified PC telomeres do not specifically coimmunoprecipitate with modified BF DNA. N ote that immunoprecipitation of VSG genes linked to telomeric repeats was consistently more efficient than that of VSG genes al one. Therefore, the smear upstream of the 121 telomere (sup), which is enriched on immunoprecipitation, is most likely attributable to cross-hybridization of the 121 probe to other VSG genes associated with telomeric tracts.

scription of the expression site reads through into the downstream telomeric repeats (Rudenko and Van der Ploeg 1989), and it is therefore possible that the first part of the repeat array is not modified. Transcribed repeats are thought to be sensitive to nucleases, resulting in formation of shorter telomeres during clonal propagation (Pays et al. 1983). The $12-\mathrm{kb}$ smear associated with the 121 telomeric band in clone 121a (Fig. 4D, lane 1) could be an example of such an event and the absence of detectable immunoprecipitation of this smear might be caused by a hi gher proportion of transcribed repeats compared with the longer band.

Immunoprecipitation of VSG genes linked to telomeric repeats was al ways more efficient than that of (inactive) VSG genes al one. A silent VSG gene that is still linked to telomeric repeats because of partial cleavage caused by DNA modification will therefore be enriched by immunoprecipitation. This has all owed us to identify two additional restriction enzymes that yield partial cleavage products with silenced telomeric VSG genes$\mathrm{Ncol}$ and Dral showed partial cleavage of VSG gene 121 and 1.1, and VSG gene 1.1, respectively (data not shown; see Discussion).

\section{$\mathrm{J}$ in and around expression site promoters}

The experiments described above show that $J$ is present in silenced telomeric VSG genes and in expression siteassociated telomeric tracts, the most distal sequences in the expression site. The analysis of expression site sequences other than VSG genes is complicated by the high degree of homology between expression sites (Pays et al. 1989a; Kooter et al. 1987). To study the promoter region of expression sites, we used cell lines in which the 
221 expression site was tagged with a unique sequence, the hygromycin resistance (HYG) gene (Rudenko et al . 1995; Blundell et al. 1996). In anti-J IP experiments, a small 0.6-kb segment of the HYG gene al one, either active (ES2) or silent (ES2-R1), did not bind to the antibodies (Fig. 5). A longer 1.1-kb fragment spanning the promoter element was also negative. The upstream part of the HYG gene linked to the long 50-bp repeat array, however, was immunoprecipitated, both from an inactive and an active expression site (Fig. 5). The absence of IP of the nonmodified HYG-marked 50-bp repeat fragment from PC cells (PCES2) mixed with BF 221a DNA (which does not contain a HYG gene) excludes nonspecific co-IP of these very long restriction fragments $(45 \mathrm{~kb})$. Cell lines in which a HYG gene was integrated in a 221 expression site, in which the expression site promoter was replaced by a ribosomal RNA promoter, gave the same results (data not shown). $J$ is therefore present in the long repetitive DNA stretches closely upstream of the promoter, regardless of expression site activity. The function of the 50-bp repeat arrays is not known, but hybridization studies have shown that 50 -bp repeats are invariably associated with expression site promoter sequences (Zomerdijk et al. 1990, 1991; G. Rudenko and P. Borst, unpubl.).

The presence of $\mathrm{J}$ at the borders of expression sites
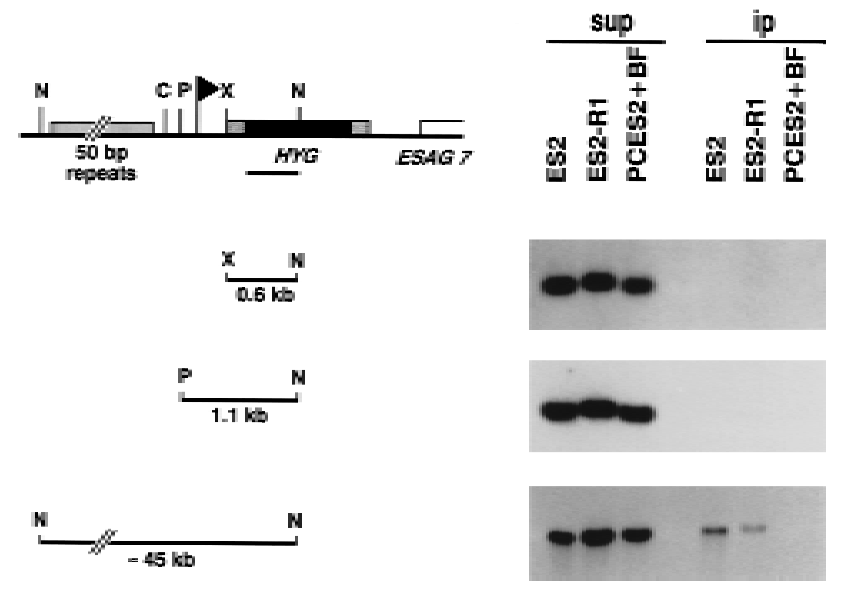

Figure 5. Detection of $\mathrm{J}$ in the 50-bp repeats upstream of inactive and active expression sites. Cell lines with a HYG gene in an active (ES2) or inactive (ES2-R1) 221 expression site were used for anti-J immunoprecipitation of sequences in and around the expression site promoter (flag). (N) N col; (C) Clal; (P) H pal; (X) Xbal. The 5' part of the HYG gene (line underneath the map) was used as a probe to specifically detect the tagged expression site sequences. The fragments analyzed are indicated on the left of each panel and include from top to bottom HYG gene al one, HYG gene linked to expression site promoter sequences, and HYG gene linked to the 50-bp repeat array. DNA of PC cells with a HYG gene downstream of the expression site promoter (PCES2) was mixed with wild-type BF 221a DN A (BF) as a negative control for nonspecific coimmunoprecipitation of nonmodified DNA. The solid box indicates the HYG-coding sequence, stippled boxes RN A-processing signals, and the striped box 50-bp repeats. prompted us to test whether sequences in between the VSG gene and the promoter are modified in inactive expression sites. The lack of probes specific for individual expression sites in this region only al lowed gl obal analysis of the total pool of expression sites. Therefore, genomic DN A was sonicated and analyzed by $\alpha$-immunoprecipitation combined with dot-blot hybridization. Because all sequences are sonicated to the same size range (0.5-3 kb), the relative efficiency of immunoprecipitation could be used as a measure for the density of modification (see also Fig. 3). Telomeric repeats, 50-bp repeats, inactive VSG genes, and al so 70-bp repeats, which are just upstream of VSG genes, were immunoprecipitated efficiently (Fig. 6). Expression site promoter and ESA G 1 fragments bound inefficiently, and other ESAGs bound even more inefficiently to the antibodies, al beit still three to four times more than chromosome-internal DN A, such as tubulin genes or ribosomal 18S DNA (Fig. 6). These results show that expression site sequences are only sparsely modified outside the VSG gene and the repeats. Whether expression site promoter and ESAG 1 genes are really modified more densely than the other ESAGs, or whether the greater immunoselection is caused by linkage to modified 50 - or 70-bp repeats is uncertain. We could not use sonicated DNA fragments shorter than 500 bp because this resulted in hi gher background IP. It should also be noted that 70-bp repeats and copies of some ESAGs (but not all) are also present outside of expression sites. Whether these outsiders are al so modified and contribute to the immunoprecipitated fraction is not known.

We also analyzed the 70-bp repeats in a specific expression site using their linkage to the unique VSG pseudogene $(\Psi)$, which is embedded in the 70-bp repeats in the 221 expressi on site (Bernards et al. 1985; Cornelissen et al. 1985). With restriction fragments of $\sim 9.5 \mathrm{~kb}$ (Hindl II) and $6.5 \mathrm{~kb}$ (Bgll, N col) containing the 70-bp repeat array and (part of) the pseudo gene, we found efficient immunoprecipitation ( $(5 \%)$ with the inactive 221 expression site from clone $121 \mathrm{a}$ and no antibody binding of the transcribed fragment from clone 221a (data not shown). These results show that J is absent from VSG genes and 70-bp repeats in active expression sites and suggest that transcribed ESAGs al so lack J.

\section{Discussion}

Partial cleavage by Pstl, Pvull, and other restriction enzymes suggested previously the presence of DNA modifications in silenced tel omeric VSG genes in BF T. brucei (Bernards et al. 1984b; Pays et al. 1984). To test whether this is caused by J, we first verified that the presence of $\mathrm{J}$ in a Pvull restriction site blocks cleavage by Pvull enzyme (Fig. 1). Interestingly, a J replacing T only two positions away from the Pvull site did not block cleavage, showing that J does not affect cleavage at a distance. By anti-J DNA immunoprecipitations, we subsequently found that J correlates with silencing of telomeric VSG genes. An inverse correlation between DNA modification and transcription of specific genes, as has been 
van Leeuwen et al.

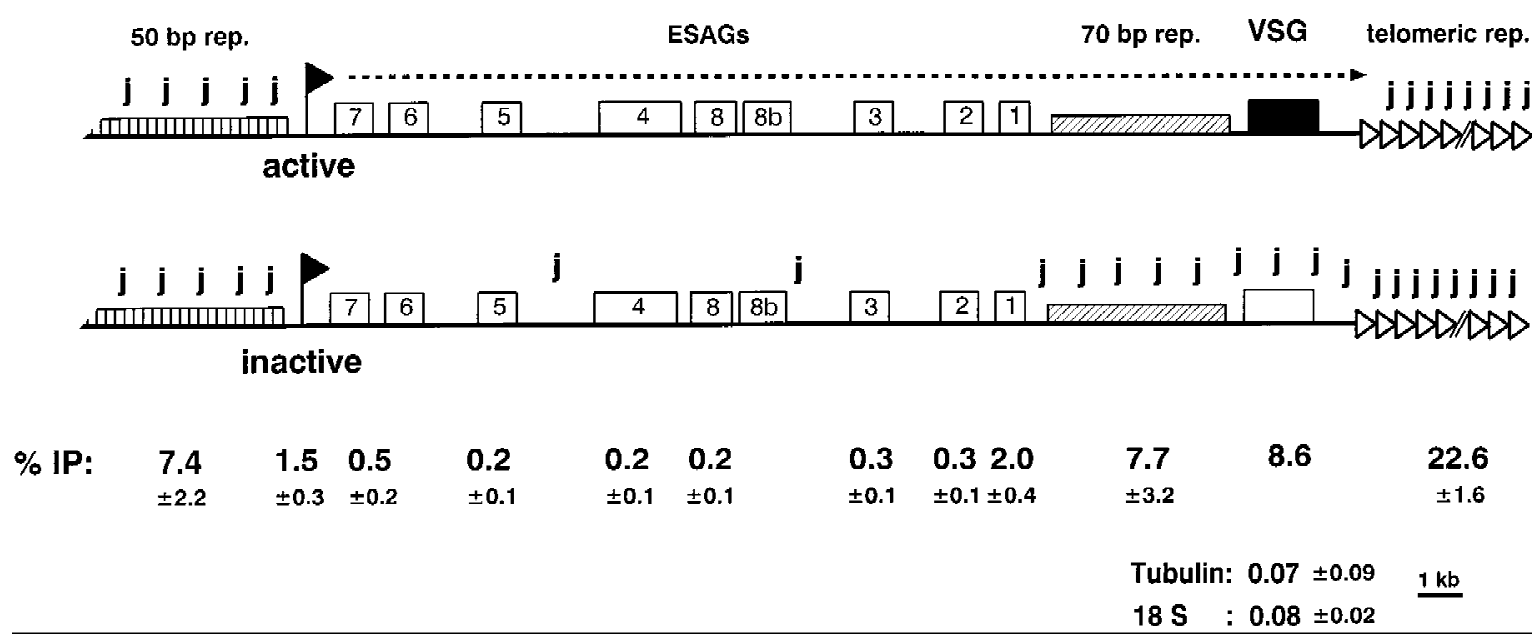

Figure 6. The modified base J in and around tel omeric VSG expression sites. Schematic representation of the distribution of $J$ in active and inactive VSG expression sites determined by $\alpha$ immunoprecipitation of sonicated DN A combined with dot-blot hybridizations (expression site adapted from Revelard et al. 1990). ES probes are described in Materials and M ethods. ESAGs were studied as the cumulative signal of all copies in the genome using sonicated DN A. Tel omeric repeats, 50-bp repeats, 70-bp repeats, VSG genes, and promoter regions were also studied in individual expression sites using restriction digests. \% IP shows a quantitation of the IP efficiency (immunoprecipitated fraction of the input) of expression site sequences using sonicated DNA (average with standard deviation of two independent clones $221 \mathrm{a}$ and $221 \mathrm{aR} 12)$. The numbers correspond to the expression site sequences shown above. IP of silent VSG genes in expression sites varied from $1( \pm 0.1)$ to $16.2( \pm 3.4)$ depending on the VSG gene studied. The absence of J in actively transcribed VSG genes and 70-bp repeats strongly suggests that J is al so absent from active ESAGs, but this has not been tested directly.

found for $5 \mathrm{MeC}$ in complex eukaryotes, has not been found before in simple eukaryotes (Rae and Steel e 1978; Blackburn et al. 1983; Capowski et al. 1989; Bird 1995; Jabl onka and Regev 1995; T weedie et al. 1997).

By anti-J immunoprecipitations, J was also found in expression site sequences in which DNA modification previously remained undetected. The boundaries of expression sites, marked by long upstream 50-bp repeat arrays and long downstream telomeric repeat arrays, were modified substantially, regardl ess of expression site activity. By studying the total pool of expression sites with immunopreci pitations of sonicated DNA, we found low levels of J around the expression site promoter and in the ESAGs. No J was detected in a promoter fragment derived from a silent expression site and tagged with a HYG gene, but specific modification of a single thymine would not have been detected in these experiments.

We conclude that J has all the properties of the modification in Pvull and Pstl restriction sites detected by Bernards et al . (1984b) and Pays et al. (1984)-both are developmentally regulated, that is, are present in BF trypanosomes and are absent from PC trypanosomes, both are found in silent tel omeric VSG genes and not in active VSG genes or chromosome-internal VSG genes. The gradient of modification from tel omere to chromosome-internal found for Pstl and Pvull sites in VSG genes (Bernards et al. 1984b) correl ates with the gradient of J found from telomeric repeats (high, to VSG genes, 70-bp repeats, ESAG 1, and other ESAGs (low). With the expression site telomeres studied here, no correlation was found between the length of the telomeric repeat array and the levels of J in VSG genes. Possibly the size difference of the individual telomeres studied was not great enough to cause a difference in immunoprecipitation.

The abundance of $J$ in different repetitive DNA sequences, such as the telomeric, 50- and 70-bp repeats (Fig. 6), and the 177-bp repeats (data not shown), shows that the modifying enzyme (complex) that introduces J into DNA has a preference for repetitive DNA that is associated to telomeres. In addition to tandem repeats, however, VSG genes were also modified. The restriction of J to silent telomeric copies of VSG genes and the gradient of modification from telomere to chromosome-internal can be explained by an enzyme that recognizes telomeric repeats and that slides down the neighboring DNA, as proposed by Bernards et al. (1984b). Alternatively, the repetitive DNA surrounding VSG genes in expression sites might impose a specific chromatin structure or sub-nuclear local ization on these VSG genes such that they also become a target for the modifying enzyme. The absence of J in transcribed telomeric VSG genes and 70-bp repeats is compatible with a competition between transcription and DN A modification in expression sites.

The J-synthesizing enzyme seems to have a preference for certain sites, but these sites do not show a clear consensus. In the telomeric repeats, both the (TAACCC) and the (GGGTTA) $n$ strand are modified, and in the Grich strand only the second $T$ is replaced by I (van Leeuwen et al. 1996). In and around telomeric VSG genes, mainly Pvull (CAGCTG) and Pstl (CTGCAG) (Bernards et al. 1984b), but also Hindlll (AAGCTT) and Sphl 
(GCATGC) (Pays et al. 1984), and Dral (TTTAAA) and $\mathrm{N}$ col (CCATGG) (data not shown), showed partial cleavage. Unfortunately, a genomic sequencing method (Clark et al. 1994) devel oped to discriminate between T and J, was not specific enough to detect J at a certain site in a small fraction of a trypanosome population (V. Gommers-Ampt and $\mathrm{P}$. Borst, unpubl.).

What could be the function of J in trypanosomes? If J is involved in expression site control, two functions could be envisaged. First, introduction of J causes expression site inactivation. Changes in modification, for example, after DNA replication, could al low activation of silent expression sites. Second, J is a consequence of expression site silencing and could help to stably maintain the repressed state of an inactive expression site. The latter model is supported by the observed abundance of $J$ in repetitive DN A in T. brucei (described above), and by the recent finding of $\mathrm{J}$ in protozoans without antigenic variation ( $F$. van Leeuwen and P. Borst, unpubl.). Those results suggest that $\mathrm{J}$ is not specifical ly involved in control of expression sites but is likely to have a more general function in the genome. It is not clear, however, why $\mathrm{T}$. brucei would require such a function of $J$ only in the mammalian stage of the life cycle. A critical test of the function of J awaits the identification and knock-out of the enzymes that make J or the identification of inhibitors that interfere with synthesis of J.

\section{Materials and methods}

\section{Trypanosome clones and DNA}

BF trypanosome clones 221a or MiTat 1.2 (Bernards et al. 1984a), 121a or MiTat 1.6a, 118a or MiTat 1.5a (Cross 1975), 221aR12 (Zomerdijk et al. 1990), or T. brucei strain 427 (Cross and $M$ anning 1973) were grown and isol ated as described (Gommers-Ampt et al. 1991). PC trypanosomes were grown in a semidefined medium (Brun and Schönenberger 1979). Clone r51.1 arose in a single relapse experiment from clone 221a, described as 221ar2 (Bernards et al. 1984a). From this polyclonal relapse population we cloned a 1.1 expresser (determined by $\mathrm{N}$ orthern blot analysis), which was called r5-1.1. Pulsed-field gel analysis of this clone showed that the 1.1 gene and the 221 gene had exchanged their chromosomal position suggesting reciprocal telomeric exchange. VSG gene 1.1 had moved to chromosome band 15, while the 221 gene had moved to chromosome band 14. Further analysis showed that the silent 221 gene at its new position was not modified on the Pvull restriction site present in the coding sequence and showed that it was insensitive to Bal 31 exonuclease treatment (data not shown). These results indicate that the 221 gene in clone r5-1.1 had moved to a chromosome-internal position. Total genomic DN A was isolated as described (Bernards et al. 1981) and resuspended in 10 $\mathrm{mm}$ Tris- $\mathrm{HCl} / 1$ mM EDTA (pH 7.4). Digested or sonicated DN A was transferred to nitrocellulose or Hybond-N (Amersham) by standard procedures (Sambrook et al. 1989). Probes were label ed with $\left[\alpha-{ }^{32} \mathrm{P}\right] \mathrm{dATP}$ by random priming. A $5^{\prime}{ }^{32} \mathrm{P}$-label ed oligomer consisting of 5 telomeric GGGTTA repeats was used to probe for telomeric repeats. Probe fragments for subtelomeric sequence, 177 -bp repeats, 70-bp repeats, 50-bp repeats, $\beta$-tubulin gene, ribosomal DNA, and kinetoplast DNA were all described in van Leeuwen et al. (1996). Other probes used were a 360-bp BamHI-Ncol 5' HYG fragment (Blundell et al. 1996), a HindlII-
BamHI ESAG 7 fragment (Zomerdijk et al. 1990), an 870-bp Pst। pseudo VSG gene $(\Psi)$ fragment (Cornelissen et al. 1985), and an 850-bp ESAG 1 fragment (M cCulloch et al. 1997). Other ESAGspecific probe fragments were generated by $\mathrm{PCR}$ amplification (Taq polymerase with $1.5 \mathrm{~mm} \mathrm{M} \mathrm{gCl} 2,30$ cycles of $1 \mathrm{~min} 94^{\circ} \mathrm{C}$, $2 \min 55^{\circ} \mathrm{C}, 2 \min 72^{\circ} \mathrm{C}$ ) of cloned ESAG sequences from the AnT at 1.3A expression site (Pays et al. 1989b; Alexandre et al. 1988) using sense primers (sp) with a $5^{\prime}$ BamHI site (underlined) flanked by a terminal CG dinucleotide and antisense primers (asp) with a 5' Xbal site (underlined) flanked by CG. 5' part of ESAG 2 (clone pBES 2000.1, sp CGGGATCCGATGAGTGTACGAGAGAGATGC, asp CGTCTAGATGATCAGCGTCTTTCCAACC); 5' part of ESAG 3 (clone pES 200.5, sp CGGGATCCAACACAAGGATGGTGTAGGC, asp CGTCTAGACTAAATGCCCAGACTCTGGC); middle part of ESAG 8 (clone pES 200.8, sp CGGGATCCAGGGAGTTGGATATCTCCGG, asp CGTCTAGACCAGTCAAACACTGAAGTCC); 5' part of ESAG 4 (clone IES 200.10, sp CGGGATCCACTTGAGCGACCGCAATGCC, asp CGTCTAGAAACTGGCATAGCGAATACCG); middle part of ESAG 5 (clone IES 200.10, sp CGGGATCCCATACATGTAGGGAGTTCGG, asp CGTCTAGATTAGGGACTTCAACCACGGG). VSG gene-specific probes were generated from cDNAs cloned into pBluescript-a 560-bp BgllIPstl fragment of VSG gene 121 (Liu et al. 1985), an 820-bp HindlII fragment of VSG 221, a 512-bp Pstl-Ncol fragment of VSG 1.1, a 520-bp Pstl fragment of VSG 1.8, and a 520-bp EcoRIPstl fragment of VSG 118 (Michels et al. 1984), and a 600-bp EcoRI-HindIII fragment of VSG VO2 (Rudenko et al. 1995). D ot blots were scanned and quantitated on a Phosphorlmager (Fujix BAS 2000, TIN A 2.08b).

Endonuclease digestion of duplex oligonucleotides

Oligonucleotides encompassing the upper and the lower strand of the Pvull site (underlined) of the VSG 221 gene were used to generate non- or hemimodified duplex molecules. Oligos were end-labeled with [ $\gamma^{-32}$ P]ATP, purified by exclusion chromatography, and annealed to their nonlabel ed J-lacking complementary strand by gradually cooling down from $90^{\circ} \mathrm{C}$ to room temperature in $10 \mathrm{~mm}$ Tris- $\mathrm{HCl}$ (pH 7.5), $1 \mathrm{~mm}$ EDTA, $100 \mathrm{~mm}$ $\mathrm{NaCl}$; upper-T (CAGAAGGCAGCTGCAACAAG) or upper-J (CAGAAGGCAGCJGCAACAAG) was annealed to lower-T (CTTGTTGCAGCTGCCTTCTG), lower-J (CTTGTTGCAGCJGCCTTCTG), or lower-J* (CTTGTJGCAGCTGCCTTCTG). The duplex oligos were incubated for $2 \mathrm{hr}$ at $37^{\circ} \mathrm{C}$ in the appropriate restriction buffer with or without 10 units of Pvull. The products were separated by $20 \%$ native polyacrylamide gel electrophoresis (19:1, 1×TBE).

\section{Generation of J-specific polyclonal antisera}

Chemical ly synthesized JM P (Wijsman et al. 1994) was coupled to carrier proteins with a water-soluble carbodiimide [1-ethyl3-(3-dimethylaminopropyl)carbodiimide $\mathrm{HCl}$, or EDC, Sigma] according to a protocol modified from (Halloran and Parker 1966; Stollar 1980). Three micrograms of JMP and $400 \mathrm{mg}$ of EDC were mixed with $4 \mathrm{mg}$ of BSA (imject BSA, Pierce) or $4 \mathrm{mg}$ of $\mathrm{KLH}$ (Cal biochem) in $1 \mathrm{ml}$ of $\mathrm{H}_{2} \mathrm{O}$, and incubated for $20 \mathrm{hr}$ in the dark at room temperature or $37^{\circ} \mathrm{C}$, respectively. This resulted in formation of phosphoramadite conjugates through the 5 '-phosphate of JMP and the amino groups of the carrier proteins (Halloran and Parker 1966; Stollar 1980). The samples were dialyzed three times against 1000 volumes of PBS to remove the free JM P and EDC , monitored by UV absorbance (263/ $280 \mathrm{~nm}$ ) to confirm crosslinking, and subsequently stored in $10 \%$ glycerol at $-70^{\circ} \mathrm{C}$. Twelve percent of the protein-nucleo- 
tide complex was injected into rabbits. Antisera were obtained against BSA-JMP $(539 \alpha J)$ and KLH-JMP $(538 \alpha J)$.

\section{Anti J-DNA immunoblot}

DNA was denatured for 20 min on ice in $0.4 \mathrm{~N} \mathrm{NaOH}$, neutralized by adding one volume of ice-cold $2.5 \mathrm{~m}$ ammonium acetate, and blotted onto nitrocellulose using a manifold dot-blot apparatus. The filters were baked for $2 \mathrm{hr}$ at $80^{\circ} \mathrm{C}$ and blocked for 2 hr in TBST $(10 \mathrm{~mm}$ Tris- $\mathrm{HCl}$ at $\mathrm{pH} 8.0,150 \mathrm{~mm} \mathrm{NaCl}, 0.02 \%$ Tween-20) with $5 \%$ milk powder. After three washes with TBST, the blots were incubated for $2 \mathrm{hr}$ with antiserum $539 \alpha$ J, diluted 1:10,000-fold in TBST with $2 \%$ milk powder, and then washed three times with TBST. Immunodetection was performed using a horseradish peroxi dase (HRP) conjugated second antibody (CLB, The N etherlands) in 2\% milk powder in TBST, in combination with enhanced chemiluminescence $(E C L, A m-$ ersham).

\section{Generation and ligation of J-containing PCR fragments}

One antisense primer with or without one J residue and three sense primers without J were used to generate J-containing and J-less 221 VSG gene PCR fragments of different sizes with Pwo polymerase. The antisense primers used were CTTGTTGCAGCJGCCTTCTG and CTTGTTGCAGCTGCCTTCTG (221as1247), the sense primers used were 221s1129 (CGACTATATACTTGCCTATTACCG), 221s821 (ACCGTGGATCGACGACGCCTG), and 221s304 (CCAACCACTATGCCATGA). PCR fragments were purified by QIAEX gel extraction (Qiagen) and the presence or absence of J was confirmed by ${ }^{32} \mathrm{P}$-nucleotide postlabeling combined with two-dimensional TLC. For detection of anti-J immunoprecipitation the fragments were end-labeled and purified by exclusion chromatography. Part of the phosphorylated fragments were ligated for $16 \mathrm{hr}$ at $16^{\circ} \mathrm{C}$ to generate ladders of fragments with a constant ratio of $\mathrm{J} / \mathrm{bp}$.

\section{J-DNA immunoprecipitation}

Digested or sonicated DN A (2-5 $\mu \mathrm{g})$ was added to $5 \mu$ l antiserum $538 \alpha$ J in a final volume of $500 \mu \mathrm{l}$ IP buffer [TBST with $2 \mathrm{~mm}$ EDTA (TBSTE), $0.1 \mathrm{mg} / \mathrm{ml}$ of tRN A, and $1 \mathrm{mg} / \mathrm{ml}$ of BSA ], and incubated for $2 \mathrm{hr}$ at room temperature. ProtA beads (20-30 $\mu \mathrm{l}$, Repligen) were washed twice with TBSTE, preblocked for 30 min in $100 \mu \mathrm{l}$ IP buffer, and incubated for $1 \mathrm{hr}$ with the IP reaction. Ten to $20 \%$ of the supernatant was taken and used as a control for the DNA input. The bead-antibody-DNA complexes were washed four times with TBSTE and finally proteinase $\mathrm{K}$-treated at $58^{\circ} \mathrm{C}$ to release the bound DNA, which was phenol-extracted, and ethanol-preci pitated with $20 \mu \mathrm{g}$ glycogen.

\section{Acknowledgments}

We thank Magali Berberof, Pat Blundell, Inês Chaves, Mike Cross, Anita Dirks, Herlinde Gerrits, Gloria Rudenko, Ronald Plasterk, and Anton Berns for helpful discussions and critical reading of the manuscript, and $P$. Blundell and $G$. Rudenko for providing HYG-marked cell lines. We thank Ben Floot for helpful suggestions for the generation of the anti-J antisera, and $\mathrm{E}$. Pays (Université Libre de Bruxelles, Brussels) for kindly providing AnTat1.3 genomic clones. This work was supported by grants from the $\mathrm{N}$ etherlands Foundation for Chemical Research (SON), with financial support of the $\mathrm{N}$ etherlands Organization for Scientific Research (NWO).

The publication costs of this article were defrayed in part by payment of page charges. This article must therefore be hereby marked "advertisement" in accordance with 18 USC section 1734 solely to indicate this fact.

\section{References}

Alexandre, S., M. Guyaux, N.B. M urphy, H. Coquelet, A. Pays, M. Steinert, and E. Pays. 1988. Putative genes of a variantspecific antigen genetranscription unit in Trypanosoma brucei. Mol. Cell. Biol. 8: 2367-2378.

Bernards, A., L.H. Van der Ploeg, A.C. Frasch, P. Borst, J.C. Boothroyd, S. Coleman, and G.A. Cross. 1981. Activation of trypanosome surface glycoprotein genes involves a duplication-transposition leading to an altered $3^{\prime}$ end. Cell 27: 497505.

Bernards, A., P.A.M. Michels, C.R. Lincke, and P. Borst. 1983. Growth of chromosome ends in multiplying trypanosomes. Nature 303: 592-597.

Bernards, A., T. de Lange, P.A. Michels, A.Y. Liu, M.J. Huisman, and $P$. Borst. 1984a. Two modes of activation of a single surface antigen gene of Trypanosoma brucei. Cell 36: 163170.

Bernards, A., N. van Harten-Loosbroek, and P. Borst. 1984b. Modification of telomeric DNA in Trypanosoma brucei; a role in antigenic variation? Nucleic Acids Res. 12: 41534170.

Bernards, A., J.M. Kooter, and P. Borst. 1985. Structure and transcription of a tel omeric surface antigen gene of Trypanosoma brucei. Mol. Cell. Biol. 5: 545-553.

Bird, A.P. 1995. Gene number, noise reduction and biological complexity. Trends Genet. 11: 94-100.

Blackburn, E.H., W.C. Pan, and C.C. Johnson. 1983. Methylation of ribosomal RNA genes in the macronucleus of Tetrahymena thermophila. Nucleic Acids Res. 11: 5131-5145.

Blundell, P.A., G. Rudenko, and P. Borst. 1996. Targeting of exogenous DNA into Trypanosoma brucei requires a high degree of homology between donor and target DNA. Mol. Biochem. Parasitol. 76: 215-229.

Borst, P., W. Bitter, P.A. Blundell, M .A. Cross, R. McCulloch, G. Rudenko, M.C. Taylor, and F. van Leeuwen. 1997. The expression sites for variant surface glycoproteins of Trypanosoma brucei. In Trypanosomiasis and Leishmaniasis (ed. G. Hide, J.C. Mottram, G.H. Coombs, and P.H. Holmes), pp. 109-131. BSP/CAB International, Oxford, UK.

Brun, R. and M. Schönenberger. 1979. Cultivation and in vitro cloning of procyclic culture forms of Trypanosoma brucei in a semi-defined medium. Acta Trop. 36: 289-292.

Capowski, E.E., J.M. Wells, G.S. Harrison, and K.M. Karrer. 1989. Molecular analysis of N6-methyladenine patterns in Tetrahymena thermophila nuclear DNA. Mol. Cell. Biol. 9: 2598-2605.

Clark, S.J., J. Harrison, C.L. Paul, and M. Frommer. 1994. High sensitivity mapping of methylated cytosines. Nucleic Acids Res. 22: 2990-2997.

Cornel issen, A.W., P.J. Johnson, J.M . Kooter, L.H. Van der Ploeg, and P. Borst. 1985. Two simultaneously active VSG gene transcription units in a single Trypanosoma brucei variant. Cell 41: 825-832.

Cross, G.A. 1975. Identification, purification and properties of clone-specific glycoprotein antigens constituting the surface coat of Trypanosoma brucei. Parasitology 71: 393-417.

-_- 1996. Antigenic variation in trypanosomes: Secrets surface slowly. BioEssays 18: 283-291.

Cross, G.A. and J.C. Manning. 1973. Cultivation of Trypanosoma brucei sspp. in semi-defined and defined media. Para- 
sitology 67: 315-331.

Crozatier, M., R.J. De Brij, L. Den Engelse, P.J. Johnson, and P. Borst. 1988. N ucleosi de analysis of DN A from Trypanosoma brucei and Trypanosoma equiperdum. Mol. Biochem. Parasitol. 31: 127-131.

Gommers-Ampt, J., J. Lutgerink, and P. Borst. 1991. A novel DN A nucleotide in Trypanosoma brucei only present in the mammalian phase of the life-cycle. Nucleic Acids Res. 19: 1745-1751.

Gommers-Ampt, J.H., F. van Leeuwen, A.L. de Beer, J.F. Vliegenthart, M. Dizdaroglu, J.A. Kowalak, P.F. Crain, and P. Borst. 1993. $\beta$-D-glucosyl-hydroxymethyluracil: A novel modified base present in the DN A of the parasitic protozoan T. brucei. Cell 75: 1129-1136.

Halloran, M.J. and C.W. Parker. 1966. The preparation of nucleotide-protein conjugates: Carbodiimides as coupling agents. J. I mmunol. 96: 373-378.

Horn, D. and G.A.M. Cross. 1995. A devel opmentally regulated position effect at a telomeric locus in Trypanosoma brucei. Cell 83: 555-561.

- - 1997. Analysis of Trypanosoma brucei vsg expression site switching in vitro. Mol. Biochem. Parasitol. 84: 189201.

Huang, L.H., C.M. Farnet, K.C. Ehrlich, and M. Ehrlich. 1982. Digestion of highly modified bacteriophage DNA by restriction endonucleases. Nucleic Acids Res. 10: 1579-1591.

Jablonka, E. and A. Regev. 1995. Gene number, methylation and biological complexity. Trends Genet. 11: 383-384.

Kooter, J.M., H.J. van der Spek, R. Wagter, C.E. d'Oliveira, F. van der Hoeven, P.J. Johnson, and P. Borst. 1987. The anatomy and transcription of a telomeric expression site for variantspecific surface antigens in T. brucei. Cell 51: 261-272.

Kornberg, S.R., S.B. Zimmerman, and A. Kornberg. 1961. Glucosylation of deoxyribonucleic acid by enzymes from bacteriophage-infected Escherichia coli. J. Biol. Chem. 236: 14871493.

Liu, A.Y., P.A. Michels, A. Bernards, and P. Borst. 1985. Trypanosome variant surface glycoprotein genes expressed early in infection. J. Mol. Biol. 182: 383-396.

McClelland, M., M. Nelson, and E. Raschke. 1994. Effect of site-specific modification on restriction endonucleases and DNA modification methyltransferases. Nucleic Acids Res. 22: 3640-3659.

McCulloch, R., G. Rudenko, and P. Borst. 1997. Gene conversions mediating antigenic variation in Trypanosoma brucei can occur in VSG expression sites lacking 70 bp repeat sequences. Mol. Cell. Biol. 17: 833-843.

Michels, P.A., L.H. Van der Ploeg, A.Y. Liu, and P. Borst. 1984. The inactivation and reactivation of an expression-linked gene copy for a variant surface glycoprotein in Trypanosoma brucei. EMBO J. 3: 1345-1351.

Pays, E., M. Laurent, K. Delinte, N. Van Meirvenne, and M. Steinert. 1983. Differential size variations between transcriptionally active and inactive tel omeres of Trypanosoma brucei. Nucleic Acids Res. 11: 8137-8147.

Pays, E., M.F. Delauw, M. Laurent, and M. Steinert. 1984. Possible DNA modification in GC dinucleotides of Trypanosoma brucei telomeric sequences; relationship with antigen gene transcription. Nucleic Acids Res. 12: 5235-5247.

Pays, E., H. Coquel et, A. Pays, P. T ebabi, and M. Steinert. 1989a. Trypanosoma brucei: Posttranscriptional control of the variable surface glycoprotein gene expression site. Mol. Cell. Biol. 9: 4018-4021.

Pays, E., P. Tebabi, A. Pays, H. Coquelet, P. Revelard, D. Sal mon, and M. Steinert. 1989b. The genes and transcripts of an antigen gene expression site from T. brucei. Cell 57: 835-
845.

Pays, E., L. Vanhamme, and M. Berberof. 1994. Genetic controls for the expression of surface antigens in African trypanosomes. [Review]. Annu. Rev. Microbiol. 48: 25-52.

Rae, P.M . and R.E. Steele. 1978. M odified bases in the DN As of unicellular eukaryotes: An examination of distributions and possible roles, with emphasis on hydroxymethyluracil in dinoflagellates. Biosystems 10: 37-53.

Revelard, P., S. Lips, and E. Pays. 1990. A gene from the VSG expression site of Trypanosoma brucei encodes a protein with both leucinerich repeats and a putative zinc finger. Nucleic Acids Res. 18: 7299-7303.

Rudenko, G., P.A. Blundell, A. Dirks-Mulder, R. Kieft, and P. Borst. 1995. A ribosomal DNA promoter replacing the promoter of a telomeric VSG gene expression site can be efficiently switched on and off in T. brucei. Cell 83: 547-553.

Rudenko, G. and L.H. Van der Ploeg. 1989. Transcription of telomere repeats in protozoa. EMBO J. 8: 2633-2638.

Sambrook, J., E.F. Fritsch, and T. Maniatis. 1989. Molecular cloning: A laboratory manual. Cold Spring Harbor Laboratory Press, Cold Spring Harbor, NY.

Stollar, B.D. 1980. The experimental induction of antibodies to nucleic acids. Methods Enzymol. 70: 70-85.

Tweedie, S., J. Charlton, V. Clark, and A. Bird. 1997. M ethylation of genomes and genes at the invertebrate-vertebrate boundary. Mol. Cell Biol. 17: 1469-1475.

Van der Ploeg, L.H., D.C. Schwartz, C.R. Cantor, and P. Borst. 1984. Antigenic variation in Trypanosoma brucei analyzed by electrophoretic separation of chromosome-sized DNA molecules. Cell 37: 77-84.

van Leeuwen, F., E.R. Wijsman, E. Kuyl-Yeheskiely, G. van der Marel, J.H. van Boom, and P. Borst. 1996. The telomeric GGGTTA repeats of Trypanosoma brucei contain the modified base J in both strands. Nucleic Acids Res. 24: 24762482.

Wijsman, E.R., O. van den Berg, E. Kuyl-Yeheskiely, G.A. van der Marel, and J.H. van Boom. 1994. Synthesis of 5-( $\beta$-Dglucopyranosyloxymethyl)-2'-deoxyuridine and derivatives thereof. A modified d-nucleoside from the DNA of Trypanosoma brucei. Rec. Trav. Chim. Pays-Bas 113: 337-338.

Zomerdijk, J.C., M. Ouellette, A.L. ten Asbroek, R. Ki eft, A.M. Bommer, C.E. Clayton, and P. Borst. 1990. The promoter for a variant surface glycoprotein gene expression site in Trypanosoma brucei. EMBO J. 9: 2791-2801.

Zomerdijk, J.C., R. Kieft, M. Duyndam, P.G. Shiels, and P. Borst. 1991. Antigenic variation in Trypanosoma brucei: A telomeric expression site for variant-specific surface glycoprotein genes with novel features. Nucleic Acids. Res. 19: 1359-1368. 


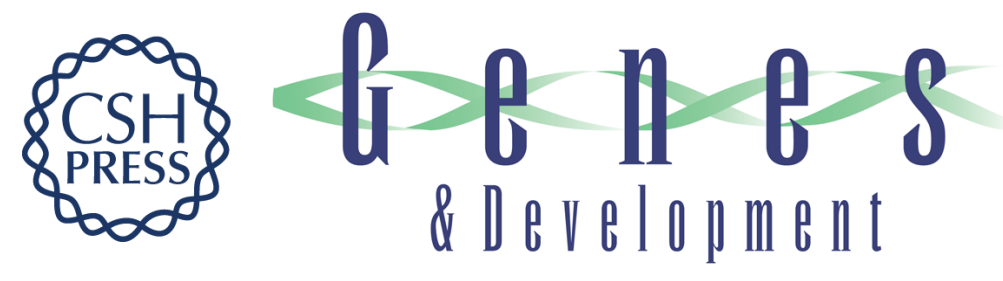

\section{Localization of the modified base $\mathrm{J}$ in telomeric VSG gene expression sites of Trypanosoma brucei}

Fred van Leeuwen, Eric R. Wijsman, Rudo Kieft, et al.

Genes Dev. 1997, 11:

Access the most recent version at doi:10.1101/gad.11.23.3232

References This article cites 46 articles, 8 of which can be accessed free at:

http://genesdev.cshlp.org/content/11/23/3232.full.html\#ref-list-1

License

Email Alerting

Receive free email alerts when new articles cite this article - sign up in the box at the top

Service right corner of the article or click here.

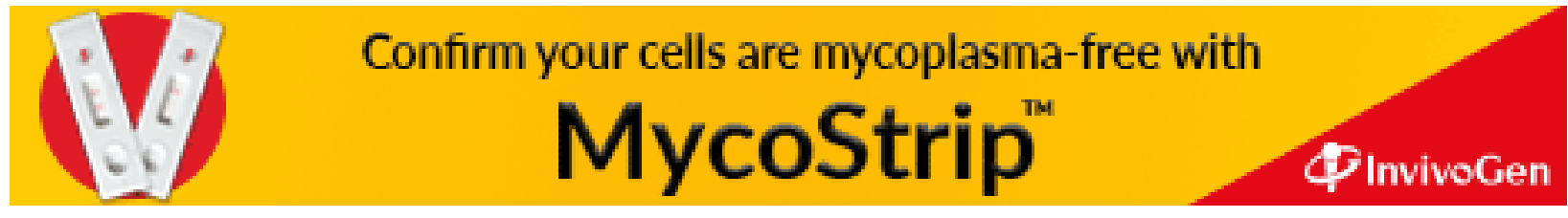

